\title{
Lifestyle Adjustments in Long-COVID Management: Potential Benefits of Plant-Based Diets
}

\author{
Maximilian Andreas Storz ${ }^{1}$ (D)
}

Accepted: 28 July 2021 / Published online: 10 September 2021

(c) The Author(s) 2021

\begin{abstract}
Purpose of Review The SARS-CoV-2-pandemic has caused mortality and morbidity at an unprecedented global scale. Many patients infected with SARS-CoV-2 continue to experience symptoms after the acute phase of infection and report fatigue, sleep difficulties, anxiety, and depression as well as arthralgia and muscle weakness. Summarized under the umbrella term "long-COVID," these symptoms may last weeks to months and impose a substantial burden on affected individuals. Dietary approaches to tackle these complications have received comparably little attention. Although plant-based diets in particular were shown to exert benefits on underlying conditions linked to poor COVID-19 outcomes, their role with regard to COVID-19 sequelae is yet largely unknown. Thus, this review sought to investigate whether a plant-based diet could reduce the burden of long-COVID.

Recent Findings The number of clinical trials investigating the role of plant-based nutrition in COVID-19 prevention and management is currently limited. Yet, there is evidence from pre-pandemic observational and clinical studies that a plantbased diet may be of general benefit with regard to several clinical conditions that can also be found in individuals with COVID-19. These include anxiety, depression, sleep disorders, and musculoskeletal pain. Adoption of a plant-based diet leads to a reduced intake in pro-inflammatory mediators and could be one accessible strategy to tackle long-COVID associated prolonged systemic inflammation.

Summary Plant-based diets may be of general benefit with regard to some of the most commonly found COVID-19 sequelae. Additional trials investigating which plant-based eating patterns confer the greatest benefit in the battle against long-COVID are urgently warranted.
\end{abstract}

Keywords SARS-CoV-2; Long-COVID $\cdot$ Plant-based diet · Vegan $\cdot$ Nutrition $\cdot$ Economic burden

\section{Introduction}

The SARS-CoV-2-pandemic has caused mortality and morbidity at an unprecedented global scale [1]. On May 30, 2021, the World Health Organization reported over 169 million cumulative cases, with over 3.5 million deaths worldwide [2]. While early attention focused on acute illness management, recent studies suggested that some patients

This article is part of the Topical Collection on Public Health Nutrition.

Maximilian Andreas Storz

maximilian.storz@uniklinik-freiburg.de

1 Centre for Complementary Medicine, Institute for Infection Prevention and Hospital Epidemiology, Faculty of Medicine, University of Freiburg, Freiburg im Breisgau, Germany continue to experience symptoms and complications after the acute phase of infection $[3,4]$. These symptoms may last weeks to months after initial recovery [5] and were summarized under the umbrella term "long-COVID" [6].

Up to $80 \%$ of patients infected with SARS-CoV-2 develop at least one long-term symptom [5], including fatigue, headaches, cognitive disturbances, sleep difficulties, anxiety, and depression as well as arthralgia, muscle weakness, dyspnea, and chest pain [1, 5, 7-10].

Affected individuals may require long-term support as studies suggest that many COVID-19 survivors will face impairments regarding their mental health or physical function far beyond hospital discharge [11]. Therefore, an increasing number of physicians have called for coordinated attempts to understand the overall survivorship burden associated with this condition [12] leading to a debate about how healthcare professionals should manage long-COVID [13]. 
The care of this particularly vulnerable patient population requires a multidisciplinary approach [14], and some experts suggest that resource allocation should prioritize rehabilitation and psychological support over advanced diagnostics and specialist respiratory service [13]. Cost-efficient and widely applicable public health strategies concomitantly improving many of the aforementioned long-COVID related symptoms are urgently warranted.

Although the World Health Organization emphasizes that alterations in diet have strong effects on health throughout life [15], dietary approaches to tackle long-COVID-related symptoms have received comparably little attention [16, 17].

Some authors and non-profit organizations, including the Physicians Committee for Responsible Medicine, highlighted the benefits of a healthy plant-based diet in fighting underlying conditions linked to poor COVID-19 outcomes $[18,19]$. As defined by Ostfeld, a plant-based diet consists of (minimally processed) fruits, vegetables, whole grains, and legumes, while excluding all animal products (such as red meat, poultry, fish, and dairy) [20]. While there are varying definitions of plant-based eating patterns [21], all of them are defined in terms of low frequency of consumption of animal foods [22]. Instead, plant-based diets emphasize vegetables, legumes, fruits, whole grains, nuts, herbs, and seeds [23]. Such a diet is abundant in fiber, antioxidants, and phytochemicals, while free of cholesterol and low in (saturated) fat and pro-inflammatory animal-derived molecules [24-27].

Recent research centered around whole-food plant-based nutrition, which is characterized by an unrestricted consumption of (whole) plant-based foods and the exclusion of both animal-based and processed foods, such as added oils, fried products, and sugary packaged items [21]. In this review, the authors examine published work on healthbenefits associated with such a plant-based dietary pattern and use the term "plant-based" to collectively refer to all plant-based eating patterns where the majority of energy is derived from plant foods. Where appropriate, specific terms (e.g., lacto-ovo-vegetarian or vegan) are used.

This narrative review considers nutrition as an accessible lifestyle modification that could reduce the burden of long-COVID on quality of life. This review also summarizes further studies that are necessary to support the postulated benefits of plant-based nutrition on long-COVID.

\section{Plant-Based Diets and COVID-19}

Clinical studies examining the effects of a plant-based diet in COVID-19 prevention and management are (yet) scarce. A very recently published population-based case-control study in six countries investigated the association between dietary patterns and COVID-19. Following a plant-based dietary pattern was associated with $73 \%$ lower odds of moderate-to-severe COVID-19-like illness [28••]. In contrast, those individuals following "low carbohydrate, high protein diets" had a substantially greater odds of moderate-to-severe COVID-19. The reservation must be made, however, that conclusions of this study were based on a rather small sample of cases (in a selected cohort of healthcare workers at the COVID-19 frontline) and that diet was self-reported.

Whether a plant-based diet might be useful to alleviate symptoms related to long-COVID has not (yet) been examined in clinical trials. Nevertheless, there is evidence from epidemiological, observational, and clinical studies done in the pre-pandemic era that a plant-based dietary pattern may be of general benefit with regard to some clinical conditions that can also be found in individuals with COVID-19. These include fatigue, sleep disorders, headaches, anxiety, and depression as well as musculoskeletal pain.

\section{Mental Health}

The COVID-19 pandemic has caused significant damage to public mental health [29]. Studies from China and Hong Kong revealed an increasing prevalence of depression and anxiety within the general public [30, 31]. In an early survey among Hong Kong citizens, $25.4 \%$ reported that their mental health had deteriorated since the pandemic [31]. Young US adults reported higher rates of loneliness, high levels of COVID-19-specific worry, and low distress tolerance [32]. In an Italian sample, 55\% of participants presented a clinical score for at least one mental disorder [33].

Affected individuals could benefit from targeted nutritional interventions promoting plant-based eating patterns. Some studies suggest that emotional health is closely associated with fruit and vegetable consumption [34, 35]. While people with poor diets tend to be less happy and healthy [34], a dose-response relationship was found between daily servings of fruits and vegetables and both life satisfaction and optimism [36]. In particular, optimism, a much needed emotion in current times, was associated with higher vegetable consumption and greater serum carotenoid concentrations [37-39] (plant pigments naturally found in abundance in vegetables and fruits [40]).

Poor nutrition may contribute to poor mental health [41, 42], particularly with regard to depression and anxiety [43]. Individuals suffering from either condition reported lower fruit and vegetable intakes and consumed higher amounts of added sugars [44]. Processed foods including sweetened desserts, processed meats, refined grains, and high-fat dairy products were associated with increased odds of depression in the Whitehall II prospective cohort [45]. This was reinforced by a recent meta-analysis revealing an association 
between meat consumption and a moderately higher incidence of depression [46].

In contrast, vegetarians who regularly eat plenty of fruits and vegetables reported significantly fewer negative emotions compared to omnivores in a cross-sectional study in healthy Seven Day Adventists [47]. Vegetarians are also to less likely to suffer from depression [48]. The reservation must be made, however, that individuals on a plant-based diets may generally be healthier [47] and reported a higher quality of life in several studies $[49,50]$. Thus, results from the aforementioned studies must be interpreted with great caution and do not allow to state unambiguously that fruit and vegetable intake directly influence mental health, as the reverse causation is also possible [35]. Yet, plant-based eating patterns are high in polyphenols and antioxidants, which were associated with beneficial effects on cognitive and mental health [51].

\section{Antioxidants and Polyphenols}

Both are readily found in plant foods and were shown to influence cerebral blood flow, cellular energy metabolism, and modulate signaling pathways of molecules involved with brain plasticity [52-55]. Naturally occurring dietary polyphenols, found in apples, plums, cherries, onions, and tea, exhibit antidepressant activity with relatively low doses $(0.3-2 \mathrm{mg} / \mathrm{kg}$ ) and are an effective means to prevent (or delay) both anxiety and depression [53]. Quercetin, a polyphenol phytochemical compound found exclusively in plant foods $[56,57]$, is probably the most prominent example.

Quercetin acts as a dietary monoamine oxidase (MAO) inhibitor, preventing the degradation of monoamine neurotransmitters such as serotonin, norepinephrine, and dopamine [58]. The serotonin theory of depression postulates that depression is the consequence of an excessive breakdown of monoamine neurotransmitters subsequent to a pathologically upregulated catalytic activity of MAO-A (Fig. 1) [59, 60].

Quercetin was shown to decrease this neurotransmitter breakdown [58] and prevented depression-like behavior in animal studies [61-63]. It is exclusively found in plantfoods; thus, a plant-based eating pattern abundant in fruits, vegetables, and legumes enhances its intake and has been proposed as a promising approach for the prevention and treatment of anxiety and depression [53]. Although quercetin also possesses antiviral properties [64, 65], it has not yet been tested in a clinical trial in patients suffering from COVID-19.

\section{Fatty Acids, Mental Health, and COVID-19}

Another frequently encountered nutritional approach to improve mental health is the increased consumption or supplementation of omega-3 fatty acids [66]. Omega-3 fatty acids have anti-inflammatory and immunomodulatory properties $[67,68]$ and were tested in several recent trials in patients suffering from COVID-19. A higher omega-3 index was associated with a lower risk of death from COVID-19 [69], as well as with improvements in several parameters of respiratory and renal function in critically ill COVID19 patients [70]. Moreover, omega-3 fatty acids have been suggested to strengthen psychological resilience during the COVID-19 pandemic [71].

Interventional studies investigating the role of omega-3 fatty acids in individuals with long-COVID are currently not existent. Although omega- 3 fatty acids can be obtained from fatty fish [72], some smaller pre-pandemic studies suggested that a diet free of fish (and other animal products) may be better for mood improvement [73]. In 2012, Beezhold and colleagues randomized 39 omnivores to one of three groups: (1) a control group consuming meat, fish, and poultry daily, (2) a group consuming fish 3-4 times weekly but avoiding poultry and meat, and finally, (3) a lacto-ovo vegetarian group avoiding meat, fish, and poultry [74]. Within just 2 weeks, participants in the second group substantially increased their omega-3 intake ( 270-364 mg/ day of eicosapentaenoic acid (EPA) docosahexaenoic acid (DHA)). Their mood scores, however, remained unchanged (as measured by the Profile of Mood States questionnaire and the Depression Anxiety and Stress Scale). Although the vegetarian group reduced their EPA and DHA intake, their mood scores improved significantly. The authors concluded that consuming a diet high in fish may not beneficially affect mental state, an important consideration with regard to declining public mental health subsequent to the COVID-19 pandemic [29].

One potential explanation is that participants in the second group significantly increased their intake of saturated fat, cholesterol and arachidonic acid (AA) [74]. AA, an omega-6 (n-6) polyunsaturated fatty acid (PUFA), is a precursor to a number of potent pro-inflammatory mediators, such as leukotrienes and prostaglandins [75, 76]. Pathologically elevated levels of these pro-inflammatory cytokines have been repeatedly associated with adverse effects on neurotransmitters [77] and elevated levels of inflammation were found in men with anxiety disorders [78]. The study by Beezhold et al. [74] suggests that even the higher dietary intake of fish-derived EPA and DHA, which are generally considered anti-inflammatory [79], failed to compensate for the harmful pro-inflammatory effects of arachidonic acid [73].

Of note, some authors also emphasized opposite findings and highlighted that fish oil supplementation is beneficial in the treatment of depression (when compared with placebo) [80]. The debate on potential therapeutic effects of omega-3 fatty acids in mental health disorders is ongoing, and randomized clinical trials have yielded inconclusive 


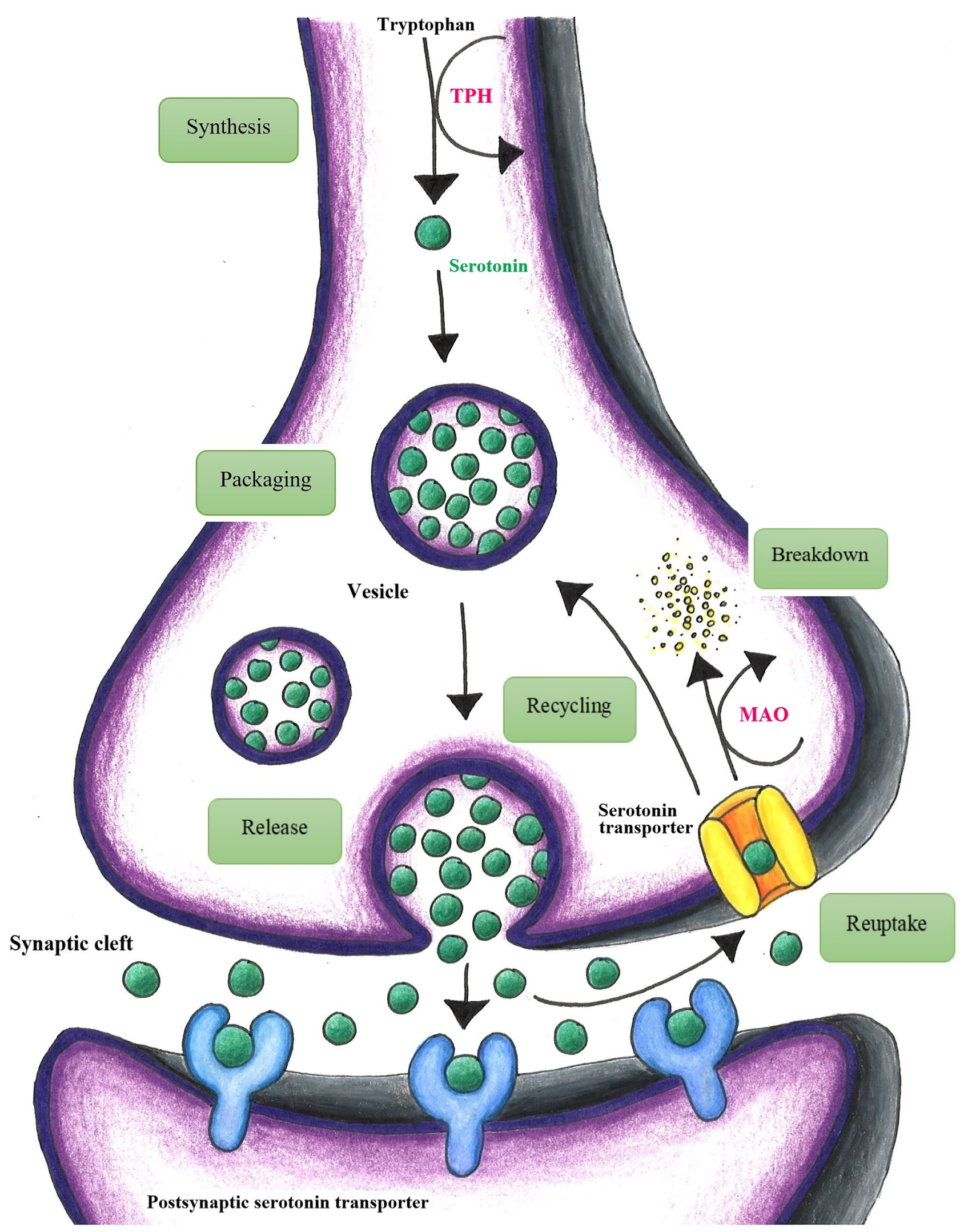

Fig. 1 The serotonin theory of depression: a schematic illustration. Quercetin inhibits the key enzyme monoamine oxidase (MAO), thereby preventing the degradation of monoamine neurotransmitters such as serotonin, norepinephrine, and dopamine (modified from [59,60]) 
results [81]. Given the fact that the aforementioned supplements also bear the potential for unwanted side effects (particularly at higher dosage levels) [81, 82], it might be advisable to set the focus on a reduced intake of potentially pro-inflammatory mediators.

Over the past decades, dietary changes toward nutrition patterns high in processed and animal foods lead to striking increases in the (n-6) to $(n-3)$ ratio $(\sim 15: 1)$ [76], whereas plant-based diets were associated with more favorable fatty acid profiles [83]. Particularly, the vegan diet includes low proportions of AA [84], while simultaneously increasing PUFA intake (when expressed as a percent of total fat intake) [85]. These factors may be one reason why vegans report less stress and anxiety than omnivores [86], whereas pro-inflammatory Western diets were positively associated with depressive symptoms in both adults [87] and children [88].

In light of these findings, anti-inflammatory plantbased dietary patterns could be a potential tool to tackle the increasing public mental health burden associated with COVID-19. Although this nutritional approach has not yet been tested in COVID-19 cohorts, its neuroprotective effects (that is preserving the brain from inflammation and oxidative stress) warrant further consideration $[89,90]$. Such a diet is also abundant in tryptophan, a key element for brain functioning, mental health prevention, and the precursor of serotonin [91, 92].

\section{Neurotransmitter Balance}

Serotonin plays an essential role in the development of depression [59]. While serotonin itself cannot pass the blood-brain barrier [92], central nervous system (CNS) serotonin synthesis can be controlled by proper intake of a tryptophan-rich diet [93]. A 2015 study in 25 healthy young adults demonstrated that consuming more dietary tryptophan resulted in less depressive symptoms and decreased anxiety [94]. A tryptophan-rich diet is not only a potential protective factor against depression but also positively related to functioning in social cognition [95]. Particularly in the elderly, mild and moderate depression may be associated with a lower intake of tryptophan [96].

Several studies identified substantial alterations in tryptophan metabolism in COVID-19 patients [97, 98], and some experts suggested that COVID-19-related alteration in both tryptophan absorption and metabolism could be the underlying pathophysiology of long-COVID symptoms [99]. Thus, it appears conceivable to ensure an adequate tryptophan supply in affected individuals (particularly in those receiving interferons [100].

Tryptophan is transported into the brain via the leucinepreferring L1-system, where it competes with other large neutral amino acids (LNAA), such as valine, leucine, and isoleucine [101]. The tryptophan: LNAA ratio determines the flux of tryptophan into the brain and is of paramount importance for serotonin biosynthesis [92, 102].

Interestingly, different meals affect this ratio in different ways: a carbohydrate-rich meal increases this ratio while a protein-rich meal significantly decreases it $[92,103]$. Carbohydrate-rich meals enhance insulin secretion and subsequently stimulate the clearance of branched amino acids (valine, leucine, isoleucine) from plasma [101]. Once these amino acids are absorbed by muscle cells, tryptophan availability for CNS uptake increases. Furthermore, vegan diets were generally found to be lower in valine and isoleucine (as compared to meat-rich diets) [104], a phenomenon that may beneficially affect tryptophan CNS uptake as well.

An often-recommended approach for ideal brain tryptophan levels is to focus on high-quality plant proteins along with generous amounts of (complex and unrefined) carbohydrates, as found in abundance in fruits, vegetable, and legumes [73].

\section{Sleep Quality}

There is accumulating evidence that such a (tryptophan-rich) dietary pattern could also improve sleep quality and mitigate quarantine-related sleep problems $[105,106]$. This appears of paramount importance as the COVID-19 pandemic is now a widely recognized risk factor for sleep disorders [107]. Lockdown periods were associated with later bedtime and waking time, an increase in daytime napping and a reduction in nighttime sleep $[108,109]$. In light of the high number of individuals that experienced worse sleep during lockdown measures [110], cost-effective strategies to tackle this problem are urgently warranted.

Several studies (not directly related to COVID-19) suggest that a plant-based diet rich in fruits and vegetables can lead to improved sleep quality $[111,112]$. The most recent example is the Helsinki Business study demonstrating an association between better sleep quality and vegetable consumption [113]. In contrast, a low-fiber and a high saturated fat intake were associated with lighter, less-restorative sleep [114].

A plant-based diet restricts (or avoids) foods that were associated with impaired sleep duration and quality, including meat [115] and high-fat products [116]. Yet, it is abundant in magnesium-rich foods [117], a nutrient associated with improvements in sleep quality, length of sleep time, and sleep onset latency as well as early morning awakening $[118,119]$.

Of note, an increased dietary magnesium intake could also benefit individuals with mental and physical stress [120, 121], two highly prevalent entities during the COVID-19 pandemic. 


\section{Musculoskeletal Pain}

Plant-based eating patterns could be generally useful to combat the skyrocketing prevalence of depression, anxiety, and sleep disorders associated with the COVID-19 pandemic. However, the benefits of a plant-based diet are not limited to mental health but may also improve a number of physical conditions associated with long-COVID.

A significant proportion of long-COVID patients report persistent muscle and joint pain $[122,123]$. Nutrition was shown to play an important role in musculoskeletal wellbeing [124], as, for example, diets high in animal protein were linked to chronic pain [124]. Pain severity was also positively associated with a high fat and sugar intake [125] and a low fruit and fiber intake [126]. There is also evidence that a low intake of magnesium and folic acid contributes to chronic musculoskeletal pain [127], whereas a high magnesium intake confers protective effects [128].

A plant-based diet is abundant in these micronutrients and vitamins, while reducing (or completely restricting) animal products that are rich in pro-inflammatory metabolites and saturated fatty acids. After just 8 weeks, this particular dietary pattern improved musculoskeletal pain and functional limitations as well as quality of life in individuals suffering from chronic pain (as measured by the Short Form Health Survey and the Numeric Pain Rating Scale) in a 2018 study [129]. Moreover, a plant-based (vegan) diet improved functional status in severe osteoarthritis, rheumatoid arthritis [130] and chronic fibromyalgia symptoms [131].

Potential mechanisms of action include an increased intake of antioxidants [132] (with a subsequent neutralization of free radicals [129]), weight loss due to reduced caloric density [133, 134] (and a subsequent reduction in mechanical load), and finally, decreased exposure to proinflammatory precursors [129].

In patients with long-COVID, inflammatory pathways can remain perturbed up to 60 days after a SARS-CoV-2 infection [135•]. Adoption of a plant-based diet could be one accessible strategy to tackle this prolonged systemic inflammation often found in long-COVID [136]. The rationale behind this hypothesis is that plant-based diets have consistently been associated with favorable reductions in inflammatory biomarkers in numerous prepandemic studies [137-140].

Franco-de-Moraes et al. compared CRP levels in vegans, omnivores, and lacto-ovo-vegetarians [141]. CRP levels were significantly lower in vegans $(0.5 \mathrm{mg} / \mathrm{L}$ (0.4-1.3)) compared to lacto-ovo-vegetarians $(0.8 \mathrm{mg} / \mathrm{L}$ (0.4-1.7)) and omnivores (1.1 mg/L (0.6-2.2)). As shown by Shah and colleagues, an 8 -week (low-fat) vegan intervention can significantly reduce high-sensitivity $\mathrm{C}$-reactive protein by $32 \%$ [142 $\bullet$. These findings are supported by a 2019 study demonstrating that adherence to a healthful plant-based diet was associated with lower hs-CRP concentrations [143].

Reviewing the potential role for immunologic aberrations and long-lasting inflammatory damage in post-COVID [1], it is biologically plausible that an anti-inflammatory plantbased diet could benefit affected individuals.

\section{Plant-Based Diets and the Immune Response}

Plant-based (vegetarian) eating patterns beneficially affect biomarkers of inflammation and immune status [144]. Craddock et al. suggested that the high intake of some key nutrients and phytochemicals (e.g., resveratrol and quercetin) in groups following plant-based diets may favorably modulate their immune function [21]. While a plant-based diet cannot prevent an individual from developing COVID-19, it may lower the odds of developing moderate-to-severe COVID19-like illness (as described in the chapter plant-based diets and COVID-19) [28••].

Plant-based dietary patterns are rich in antioxidants, phytosterols, and polyphenols, which positively affect several cell types implicated in immune function [145] and exhibit direct antiviral properties [146, 147]. Commonly consumed foods including vitamins $\mathrm{A}, \mathrm{D}$, and $\mathrm{E}$ and water-soluble constituents of mushrooms as well as polyphenols found in fruits and vegetables may improve natural killer cell functionality and activity [21, 148]. Studies dating back to 1989 found an increased natural killer cell activity of peripheral blood lymphocytes in vegetarian men (when compared with omnivores) [149]. A later study in vegans by Haddad et al., however, could not confirm these findings [150]. Yet, Haddad et al. also observed lower leukocyte counts in vegans [150], a finding that was confirmed in later studies $[104,151]$.

Craddock et al. hypothesized that this phenomenon in those following plant-based dietary patterns may be beneficial [21], as elevated leukocyte counts have been associated with increased risk of type-2-diabetes and metabolic syndrome [152, 153] — both also being significant risk factors for a severe COVID-19 disease [154]. Despite these findings, the effects of a plant-based on immune function are poorly understood and future studies are warranted to investigate whether such dietary patterns may truly protect from viral illnesses.

\section{Summary}

Table 1 summarizes the main features of a plant-based diet and their potential benefits in patients with long-COVID. 
Table 1 Features of a plant-based diet and their potential benefits in long-COVID-related symptoms

\begin{tabular}{|c|c|}
\hline Features of plant-based diets & Potential benefits with regard to long-COVID-related symptoms \\
\hline High in fiber [24-26] & $\begin{array}{l}\text { A low fiber intake was associated with lighter, less restorative sleep [113]; } \\
\text { increasing fiber consumption may be beneficial with regard to long- } \\
\text { COVID-related sleep disorders }\end{array}$ \\
\hline High in antioxidants and polyphenols (e.g., quercetin) $[21,52,53]$ & $\begin{array}{l}\text { Naturally-occurring dietary polyphenols exhibit antidepressant activity [42] } \\
\text { and may be beneficial with regard to long-COVID-related mental health } \\
\text { problems } \\
\text { Antioxidants neutralize free radicals and may help to tackle prolonged sys- } \\
\text { temic inflammation often found in long-COVID [136] } \\
\text { Polyphenols positively affect several cell types implicated in immune func- } \\
\text { tion [145] and exhibit direct antiviral properties [146, 147] }\end{array}$ \\
\hline $\begin{array}{l}\text { Favorable fatty acid profile [83] (high in polyunsaturated fatty } \\
\text { acids [85], low in saturated fat, cholesterol and arachidonic acid } \\
\text { [84]) }\end{array}$ & $\begin{array}{l}\text { A high intake of (saturated) fat was associated with lighter, less restorative } \\
\text { sleep [83]; reducing saturated fat intake could potentially improve long- } \\
\text { COVID-related sleep disorders } \\
\text { A reduced intake of pro-inflammatory precursor might help tackle prolonged } \\
\text { systemic inflammation in long-COVID [136] }\end{array}$ \\
\hline High in magnesium [117] & $\begin{array}{l}\text { A higher dietary magnesium intake may improve sleep quality, length of } \\
\text { sleep time, sleep onset latency [88] and may also alleviate mental and } \\
\text { physical stress }[89,90]\end{array}$ \\
\hline Reduced caloric density [134], high nutrient density [155] & $\begin{array}{l}\text { A plant-based diet may contribute to weight loss }[134] \text { and a subsequent } \\
\text { reduction in mechanical load, an important feature with regard to long- } \\
\text { COVID-related joint and muscle pain }\end{array}$ \\
\hline
\end{tabular}

\section{Strengths and Limitations}

This narrative review has several strengths and limitations that warrant further discussion. To the best of our knowledge, it is the first narrative review that examined the potential role for plant-based eating patterns in long-COVIDrelated sequelae. The symptom-oriented approach covers some of the most commonly encountered complications found in patients with long-COVID. The present review also includes a broad spectrum of the literature and identified several (biologically) plausible mechanisms how a plantbased diet could potentially improve symptoms related to long-COVID.

At the same time, the exploratory nature of this review may be considered a major limitation. Clinical intervention studies investigating the effects of a plant-based diet in individuals with long-COVID are currently not available. Much of the authors' hypothesis is undermined by (biologically) plausible information and mechanisms; however, the vast majority of the included studies in this review was published in the pre-pandemic era and was not done in patients with COVID-19. Whether results would have been the same (or better or worse) in this particular cohort remains subject to speculation. Some of the included studies in this narrative also share a common limitation of small sample size (e.g., [47, 74]), which may limit their validity. Finally, it is important to note that individuals consuming a plant-based diet often exhibit a healthier lifestyle in general [156], which includes higher rates of physical activity [157], higher education [157, 158], and lower smoking rates [159]. Such factors may be potential confounders that warrant consideration when interpreting the results of nutritional studies and could explain the better overall health of those consuming a plant-based diet.

\section{Conclusions and Future Direction}

The SARS-CoV-2-pandemic has caused morbidity at an unprecedented global scale. Although additional research is warranted to understand the overall survivorship burden associated with long-COVID, its sequelae will most likely continue to increase in the foreseeable future. As such, healthcare systems and particularly outpatient infrastructures will face substantial challenges.

The pandemic has imposed a heavy economic burden on many countries and future public health policies might suffer from strict cost-control and rationing policies. Effective and economical strategies should therefore concomitantly tackle as many long-COVID symptoms as possible.

One such strategy could include the large-scale promotion of plant-based eating patterns, which have a substantial potential to improve both physical and mental conditions that are now frequently encountered in long-COVID. While few studies have (yet) investigated their effectiveness in this particular cohort, this review suggests that a plant-based eating pattern could potentially exert beneficial effects with regard to anxiety, depression, sleep disorders, musculoskeletal pain, and systemic inflammation - symptoms that are often reported by individuals suffering from long-COVID. 
Resource allocation should recognize this evidence and support clinical trials examining the role of plant-based nutrition and other dietary recommendations in the battle against long-COVID.

Future studies should include detailed macro- and micronutrient data and should particularly explore which plantbased eating patterns (e.g., lacto-ovo-vegetarian, vegan) confers the greatest benefits in the battle against long-COVID.

Acknowledgements The author would like to thank Maria Brommer, $\mathrm{MD}$, for providing the figures for this publication.

Author Contributions Maximilian Andreas Storz, MD, did the literature research, analyzed the data, designed and drafted the manuscript, and submitted the final version. MA Storz is the sole author of the submitted manuscript.

Funding Open Access funding enabled and organized by Projekt DEAL

Data Availability Not applicable.

\section{Declarations}

Conflict of Interest The author declares that there is no conflict of interest.

Ethical Approval Not applicable.

Consent to Participate Not applicable.

Consent for Publication Not applicable.

Human and Animal Rights This article does not contain any studies with human or animal subjects performed by any of the authors.

Open Access This article is licensed under a Creative Commons Attribution 4.0 International License, which permits use, sharing, adaptation, distribution and reproduction in any medium or format, as long as you give appropriate credit to the original author(s) and the source, provide a link to the Creative Commons licence, and indicate if changes were made. The images or other third party material in this article are included in the article's Creative Commons licence, unless indicated otherwise in a credit line to the material. If material is not included in the article's Creative Commons licence and your intended use is not permitted by statutory regulation or exceeds the permitted use, you will need to obtain permission directly from the copyright holder. To view a copy of this licence, visit http://creativecommons.org/licenses/by/4.0/.

\section{References}

Papers of particular interest, published recently, have been highlighted as:

- Of importance

$\bullet$ Of major importance
1. Nalbandian A, Sehgal K, Gupta A, Madhavan MV, McGroder C, Stevens JS, et al. Post-acute COVID-19 syndrome. Nat Med. 2021;27(4):601-15.

2. World Health Organization. COVID-19 weekly epidemiological update; [cited 2021 May 30]. Available from: https://www. who.int/docs/default-source/coronaviruse/situation-reports/ 20210601_weekly_epi_update_42.pdf?sfvrsn $=5$ b0bbc7c_5\& download=true

3. NIHR. Living with covid-19. A dynamic review of the evidence around ongoing covid-19 symptoms (often called long covid). October 2020; [cited 2021 May 30]. https://evidence.nihr.ac.uk/ themedreview/living-with-covid19.

4. Iwu CJ, Iwu CD, Wiysonge CS. The occurrence of long COVID: a rapid review. Pan Afr Med J. 2021;38:65.

5. Lopez-Leon S, Wegman-Ostrosky T, Perelman C, Sepulveda R, Rebolledo PA, Cuapio A, et al. More than 50 Long-term effects of COVID-19: a systematic review and meta-analysis. medRxiv. 2021 Jan 30;

6. Wong TL, Weitzer DJ. Long COVID and myalgic encephalomyelitis/chronic fatigue syndrome (ME/CFS)-a systemic review and comparison of clinical presentation and symptomatology. Medicina (Kaunas). 2021;57(5):418.

7. Carfî A, Bernabei R, Landi F. Gemelli against COVID-19 postacute care study group. Persistent symptoms in patients after acute COVID-19. JAMA. 2020;324(6):603-5.

8. Huang C, Huang L, Wang Y, Li X, Ren L, Gu X, et al. 6-month consequences of COVID-19 in patients discharged from hospital: a cohort study. Lancet. 2021;397(10270):220-32.

9. Logue JK, Franko NM, McCulloch DJ, McDonald D, Magedson A, Wolf CR, et al. Sequelae in adults at 6 months after COVID19 infection. JAMA Netw Open. 2021;4(2):e210830.

10. Osikomaiya B, Erinoso O, Wright KO, Odusola AO, Thomas B, Adeyemi O, et al. 'Long COVID': persistent COVID-19 symptoms in survivors managed in Lagos State, Nigeria. BMC Infect Dis. 2021;21(1):304.

11. Marra A, Pandharipande PP, Girard TD, Patel MB, Hughes CG, Jackson JC, et al. Co-occurrence of post-intensive care syndrome problems among 406 survivors of critical illness. Crit Care Med. 2018;46(9):1393-401.

12. Iqbal FM, Lam K, Sounderajah V, Elkin S, Ashrafian H, Darzi A. Understanding the survivorship burden of long COVID. EClinicalMedicine. 2021;33:100767.

13. Sykes DL, Holdsworth L, Jawad N, Gunasekera P, Morice AH, Crooks MG. Post-COVID-19 symptom burden: what is long-COVID and how should we manage it? Lung. 2021;199(2):113-9.

14. Del Rio C, Collins LF, Malani P. Long-term health consequences of COVID-19. JAMA. 2020;324(17):1723-4.

15. World Health Organization I 1. Introduction [Internet]. WHO. World Health Organization; [cited 2021 May 21]. Available from: https://www.who.int/nutrition/topics/1_introduction/en/

16. Nalbandian A, Sehgal K, Gupta A, Madhavan MV, McGroder C, Stevens JS, et al. Post-acute COVID-19 syndrome. Nat Med. 2021;27(4):601-15.

17. Holdoway A. Addressing nutrition in the road map of recovery for those with long COVID-19. Br J Community Nurs. 2021;26(5):218-22.

18. Physicians Committee for Responsible Medicine. Diet can fight diseases linked to poor COVID-19 outcomes [Internet]. Physicians Committee for Responsible Medicine; [cited 2021 May 21]. Available from: https://www.pcrm.org/news/blog/diet-canfight-diseases-linked-poor-covid-19-outcomes

19. Benavides H, Meireles CL, Benavente V, Mays MH, Wang J. Decreasing older adult COVID-19 risk factors using digital technology to implement a plant-based-diet: an opinion paper. JMIR Aging. 2021 May 31; 
20. Ostfeld RJ. Definition of a plant-based diet and overview of this special issue. J Geriatr Cardiol. 2017;14(5):315.

21. Craddock JC, Neale EP, Peoples GE, Probst YC. Plant-based eating patterns and endurance performance: a focus on inflammation, oxidative stress and immune responses. Nutr Bull. 2020;45(2):123-32.

22. Satija A, Hu FB. Plant-based diets and cardiovascular health. Trends Cardiovasc Med. 2018;28(7):437-41.

23. Storz MA. Is there a lack of support for whole-food, plant-based diets in the medical community? Perm J. 2018;23:18-068.

24. Storz MA. Will the plant-based movement redefine physicians' understanding of chronic disease? New Bioeth. 2020;26(2):141-57.

25. Trautwein EA, McKay S. The role of specific components of a plant-based diet in management of dyslipidemia and the impact on cardiovascular risk. Nutrients. 2020 Sept 1;12(9).

26. Grosse CSJ, Christophersen CT, Devine A, Lawrance IC. The role of a plant-based diet in the pathogenesis, etiology and management of the inflammatory bowel diseases. Expert Rev Gastroenterol Hepatol. 2020;14(3):137-45.

27. Medawar E, Huhn S, Villringer A, Veronica WA. The effects of plant-based diets on the body and the brain: a systematic review. Transl Psychiatry. 2019;9(1):226.

28.•• Kim H, Rebholz CM, Hegde S, LaFiura C, Raghavan M, Lloyd JF, et al. Plant-based diets, pescatarian diets and COVID-19 severity: a population-based case-control study in six countries. BMJ Nutrition, Prevention \& Health. 2021 May 18;bmjnph. This is the first high-quality case-control study that revealed that following plant-based diets is associated with $73 \%$ lower odds of moderate-to-severe COVID-19-like illness compared with individuals who did not follow these diets.

29. Rehman U, Shahnawaz MG, Khan NH, Kharshiing KD, Khursheed M, Gupta K, et al. Depression, anxiety and stress among Indians in times of covid-19 lockdown. Community Ment Health J. 2021;57(1):42-8.

30. Gao J, Zheng P, Jia Y, Chen H, Mao Y, Chen S, et al. Mental health problems and social media exposure during COVID-19 outbreak. PLoS One. 2020;15(4):e0231924.

31. Choi EPH, Hui BPH, Wan EYF. Depression and anxiety in Hong Kong during COVID-19. Int J Environ Res Public Health. 2020;17(10):3740.

32. Liu CH, Zhang E, Wong GTF, Hyun S, Chris HH. Factors associated with depression, anxiety, and PTSD symptomatology during the COVID-19 pandemic: clinical implications for US young adult mental health. Psychiatry Research. 2020;290:113172.

33. Mazza MG, De Lorenzo R, Conte C, Poletti S, Vai B, Bollettini I, et al. Anxiety and depression in COVID-19 survivors: role of inflammatory and clinical predictors. Brain Behav Immun. 2020;1(89):594-600.

34. Wilsher SH. The impact of emotional health on fruit and vegetable consumption in young men: a qualitative study. Proceedings of the Nutrition Society [Internet]. 2013 ed [cited 2021 May 24];72(OCE4). Available from: https://www.cambridge. org/core/journals/proceedings-of-the-nutrition-society/article/ impact-of-emotional-health-on-fruit-and-veget ableconsumption-in-young-men-a-quali tative-study/ 79ED3B2F9D71AC5C98AC58B62FA90D21

35. Głąbska D, Guzek D, Groele B, Gutkowska K. Fruit and vegetable intake and mental health in adults: a systematic review. Nutrients. 2020;12(1):E115.

36. Blanchflower DG, Oswald AJ, Stewart-Brown S. Is psychological well-being linked to the consumption of fruit and vegetables? Soc Indic Res. 2013;114(3):785-801.

37. Boehm JK, Williams DR, Rimm EB, Ryff C, Kubzansky LD. Association between optimism and serum antioxidants in the midlife in the United States study. Psychosom Med. 2013;75(1):2-10.

38. Kelloniemi H, Ek E, Laitinen J. Optimism, dietary habits, body mass index and smoking among young Finnish adults. Appetite. 2005;45(2):169-76.

39. Giltay EJ, Geleijnse JM, Zitman FG, Buijsse B, Kromhout D. Lifestyle and dietary correlates of dispositional optimism in men: The Zutphen Elderly Study. J Psychosom Res. 2007;63(5):483-90.

40. Bhatt T, Patel K. Carotenoids: potent to prevent diseases review. Nat Prod Bioprospect. 2020;10(3):109-17.

41. Ju S-Y, Park YK. Low fruit and vegetable intake is associated with depression among Korean adults in data from the 2014 Korea National Health and Nutrition Examination Survey. J Health Popul Nutr. 2019;38(1):39.

42. Huang P, O'Keeffe M, Elia C, Karamanos A, Goff LM, Maynard $\mathrm{M}$, et al. Fruit and vegetable consumption and mental health across adolescence: evidence from a diverse urban British cohort study. Int J Behav Nutr Phys Act. 2019;16(1):19.

43. Dharmayani PNA, Juergens M, Allman-Farinelli M, Mihrshahi $\mathrm{S}$. Association between fruit and vegetable consumption and depression symptoms in young people and adults aged 15-45: a systematic review of cohort studies. Int J Environ Res Public Health. 2021;18(2):E780.

44. Wattick RA, Hagedorn RL, Olfert MD. Relationship between diet and mental health in a young adult appalachian college population. Nutrients. 2018;10(8):957.

45. Akbaraly TN, Brunner EJ, Ferrie JE, Marmot MG, Kivimaki M, Singh-Manoux A. Dietary pattern and depressive symptoms in middle age. Br J Psychiatry. 2009;195(5):408-13.

46. Zhang Y, Yang Y, Xie M-S, Ding X, Li H, Liu Z-C, et al. Is meat consumption associated with depression? a meta-analysis of observational studies. BMC Psychiatry. 2017;17(1):409.

47. Beezhold BL, Johnston CS, Daigle DR. Vegetarian diets are associated with healthy mood states: a cross-sectional study in Seventh Day Adventist adults. Nutr J. 2010;1(9):26.

48. Shen Y-C, Chang C-E, Lin M-N, Lin C-L. Vegetarian diet is associated with lower risk of depression in Taiwan. Nutrients. 2021;13(4):1059.

49. Agarwal U, Mishra S, Xu J, Levin S, Gonzales J, Barnard ND. A multicenter randomized controlled trial of a nutrition intervention program in a multiethnic adult population in the corporate setting reduces depression and anxiety and improves quality of life: the GEICO study. Am J Health Promot. 2015;29(4):245-54.

50. Kahleova H, Hrachovinova T, Hill M, Pelikanova T. Vegetarian diet in type 2 diabetes-improvement in quality of life, mood and eating behaviour. Diabet Med. 2013;30(1):127-9.

51. Rajaram S, Jones J, Lee GJ. Plant-based dietary patterns, plant foods, and age-related cognitive decline. Adv Nutr. 2019;10(Suppl_4):422-36.

52. Gomez-Pinilla F, Nguyen TTJ. Natural mood foods: the actions of polyphenols against psychiatric and cognitive disorders. Nutr Neurosci. 2012;15(3):127-33.

53. Bouayed J. Polyphenols: a potential new strategy for the prevention and treatment of anxiety and depression. Curr Nutr Food Sci. 2010;6(1):13-8.

54. Flanagan E, Müller M, Hornberger M, Vauzour D. Impact of flavonoids on cellular and molecular mechanisms underlying age-related cognitive decline and neurodegeneration. Curr Nutr Rep. 2018;7(2):49-57.

55. Joris PJ, Mensink RP, Adam TC, Liu TT. Cerebral blood flow measurements in adults: a review on the effects of dietary factors and exercise. Nutrients. 2018;10(5):E530.

56. Tungmunnithum D, Thongboonyou A, Pholboon A, Yangsabai A. Flavonoids and other phenolic compounds from medicinal plants for pharmaceutical and medical aspects: an overview. 
Medicines (Basel) [Internet]. 2018 Aug 25 [cited 2021 May 24];5(3). Available from: https://www.ncbi.nlm.nih.gov/pmc/ articles/PMC6165118/

57. Anand David AV, Arulmoli R, Parasuraman S. Overviews of biological importance of quercetin: a bioactive flavonoid. Pharmacogn Rev. 2016;10(20):84-9.

58. Dixon Clarke SE, Ramsay RR. Dietary inhibitors of monoamine oxidase A. J Neural Transm (Vienna). 2011;118(7):1031-41.

59. Higuchi Y, Soga T, Parhar IS. Regulatory pathways of monoamine oxidase A during social stress. Front Neurosci. 2017;11:604.

60. aan het Rot M, Mathew SJ, Charney DS. Neurobiological mechanisms in major depressive disorder. CMAJ. 2009 Feb 3;180(3):305-13

61. Ismail H, Amanat MA, Iqbal A, Mirza B. Medicinal plants: a complementary and alternative antidepressant therapy. Curr Pharm Des. 2018;24(22):2609-24.

62. Bahramsoltani R, Farzaei MH, Farahani MS, Rahimi R. Phytochemical constituents as future antidepressants: a comprehensive review. Rev Neurosci. 2015;26(6):699-719.

63. Dhiman P, Malik N, Sobarzo-Sánchez E, Uriarte E, Khatkar A. Quercetin and related chromenone derivatives as monoamine oxidase inhibitors: targeting neurological and mental disorders. Molecules [Internet]. 2019 Jan 24 [cited 2021 May 24];24(3). Available from: https://www.ncbi.nlm.nih.gov/pmc/ articles/PMC6385169/

64. Agrawal PK, Agrawal C, Blunden G. Quercetin: antiviral significance and possible COVID-19 integrative considerations. Nat Prod Commun. 2020;15(12):1934578X20976293.

65. Colunga Biancatelli RML, Berrill M, Catravas JD, Marik PE. Quercetin and vitamin C: an experimental, synergistic therapy for the prevention and treatment of SARS-CoV-2 related disease (COVID-19). Front Immunol. 2020;11:1451.

66. Grosso G, Galvano F, Marventano S, Malaguarnera M, Bucolo $\mathrm{C}$, Drago F, et al. Omega-3 fatty acids and depression: scientific evidence and biological mechanisms. Oxid Med Cell Longev. 2014;2014:313570.

67. Hathaway D, Pandav K, Patel M, Riva-Moscoso A, Singh BM, Patel A, et al. Omega 3 fatty acids and COVID-19: a comprehensive review. Infect Chemother. 2020;52(4):478-95.

68. Gutiérrez S, Svahn SL, Johansson ME. Effects of omega-3 fatty acids on immune cells. Int J Mol Sci. 2019;20(20):5028.

69. Asher A, Tintle NL, Myers M, Lockshon L, Bacareza H, Harris WS. Blood omega-3 fatty acids and death from COVID19: a pilot study. Prostaglandins Leukot Essent Fatty Acids. 2021;166:102250.

70. Doaei S, Gholami S, Rastgoo S, Gholamalizadeh M, Bourbour F, Bagheri SE, et al. The effect of omega-3 fatty acid supplementation on clinical and biochemical parameters of critically ill patients with COVID-19: a randomized clinical trial. J Transl Med. 2021;19(1):128.

71. Chang JP-C, Pariante CM, Su K-P. Omega-3 fatty acids in the psychological and physiological resilience against COVID-19. Prostaglandins Leukot Essent Fatty Acids. 2020;161:102177.

72. Domingo JL. Omega-3 fatty acids and the benefits of fish consumption: is all that glitters gold? Environ Int. 2007;33(7):993-8.

73. Physicians Committee for Responsible Medicine. Food and mood: eating plants to fight the blues [Internet] [cited 2021 May 24]. Available from: https://www.pcrm.org/good-nutrition/ food-and-mood

74. Beezhold BL, Johnston CS. Restriction of meat, fish, and poultry in omnivores improves mood: a pilot randomized controlled trial. Nutr J. 2012;14(11):9.

75. Innes JK, Calder PC. Omega- 6 fatty acids and inflammation. Prostaglandins Leukot Essent Fatty Acids. 2018;132:41-8.
76. Patterson E, Wall R, Fitzgerald GF, Ross RP, Stanton C. Health implications of high dietary omega-6 polyunsaturated Fatty acids. J Nutr Metab. 2012;2012:539426.

77. Lucas M, Chocano-Bedoya P, Schulze MB, Shulze MB, Mirzaei F, O'Reilly ÉJ, et al. Inflammatory dietary pattern and risk of depression among women. Brain Behav Immun. 2014;36:46-53.

78. Vogelzangs N, Beekman ATF, de Jonge P, Penninx BWJH. Anxiety disorders and inflammation in a large adult cohort. Transl Psychiatry. 2013;3:e249.

79. Kwon SY, Massey K, Watson MA, Hussain T, Volpe G, Buckley $\mathrm{CD}$, et al. Oxidised metabolites of the omega- 6 fatty acid linoleic acid activate dFOXO. Life Sci Alliance. 2020;3(2):e201900356.

80. Burhani MD, Rasenick MM. Fish oil and depression: the skinny on fats. J Integr Neurosci. 2017;16(s1):S115-24.

81. Lange KW. Omega-3 fatty acids and mental health. Global Health J. 2020;4(1):18-30.

82. Lange KW, Nakamura Y, Gosslau AM, Li S. Are there serious adverse effects of omega- 3 polyunsaturated fatty acid supplements? J Food Bioactives. 2019. https://doi.org/10.31665/JFB. 2019.7192

83. Storz MA. The role of vegan diets in lipotoxicity-induced betacell dysfunction in type-2-diabetes. J Popl Ther Clin Pharmacol. 2020;27(SP2):e22-38.

84. Sanders TA, Roshanai F. Platelet phospholipid fatty acid composition and function in vegans compared with ageand sex-matched omnivore controls. Eur J Clin Nutr. 1992;46(11):823-31.

85. Kahleova H, Hlozkova A, Fleeman R, Fletcher K, Holubkov R, Barnard ND. Fat quantity and quality, as part of a low-fat, vegan diet, are associated with changes in body composition, insulin resistance, and insulin secretion. A 16-Week Randomized Controlled Trial. Nutrient. 2019;11(3):615.

86. Beezhold B, Radnitz C, Rinne A, DiMatteo J. Vegans report less stress and anxiety than omnivores. Nutr Neurosci. 2015;18(7):289-96.

87. Cherian L, Wang Y, Holland T, Agarwal P, Aggarwal N, Morris MC. DASH and Mediterranean-dash intervention for neurodegenerative delay (MIND) diets are associated with fewer depressive symptoms over time. J Gerontol A Biol Sci Med Sci. 2021;76(1):151-6.

88. Cong X, Tracy M, Edmunds LS, Hosler AS, Appleton AA. The relationship between inflammatory dietary pattern in childhood and depression in early adulthood. Brain Behav Immun Health. 2020;2:100017.

89. Farooqui AA, Farooqui T. Chapter 20 - Effects of Western, Mediterranean, vegetarian, and Okinawan diet patterns on human brain. In: Farooqui T, Farooqui AA, editors. Role of the Mediterranean diet in the brain and neurodegenerative diseases [Internet]. Academic Press; 2018 [cited 2021 Jul 4]. p. 317-32. Available from: https://www.sciencedirect.com/science/article/ pii/B9780128119594000201

90. Pistollato F, Battino M. Role of plant-based diets in the prevention and regression of metabolic syndrome and neurodegenerative diseases. Trends Food Sci Technol. 2014;40(1):62-81.

91. Marx W, Lane M, Hockey M, Aslam H, Berk M, Walder K, et al. Diet and depression: exploring the biological mechanisms of action. Mol Psychiatry. 2021;26(1):134-50.

92. Strasser B, Gostner JM, Fuchs D. Mood, food, and cognition: role of tryptophan and serotonin. Curr Opin Clin Nutr Metab Care. 2016;19(1):55-61.

93. Shabbir F, Patel A, Mattison C, Bose S, Krishnamohan R, Sweeney E, et al. Effect of diet on serotonergic neurotransmission in depression. Neurochem Int. 2013;62(3):324-9.

94. Lindseth G, Helland B, Caspers J. The effects of dietary tryptophan on affective disorders. Arch Psychiatr Nurs. 2015;29(2):102-7. 
95. Reuter M, Zamoscik V, Plieger T, Bravo R, Ugartemendia L, Rodriguez AB, et al. Tryptophan-rich diet is negatively associated with depression and positively linked to social cognition. Nutr Res. 2021;1(85):14-20.

96. Chojnacki C, Popławski T, Chojnacki J, Fila M, Konrad P, Blasiak J. Tryptophan intake and metabolism in older adults with mood disorders. Nutrients. 2020;12(10):E3183.

97. Thomas T, Stefanoni D, Reisz JA, Nemkov T, Bertolone L, Francis RO, et al. COVID-19 infection alters kynurenine and fatty acid metabolism, correlating with IL-6 levels and renal status. JCI Insight. 2020;5(14):140327.

98. Ansone L, Ustinova M, Terentjeva A, Perkons I, Birzniece L, Rovite V, et al. Tryptophan and arginine metabolism is significantly altered at the time of admission in hospital for severe COVID-19 patients: findings from longitudinal targeted metabolomics analysis. medRxiv. 2021;323:1239.

99. Eroğlu İ, Eroğlu BÇ, Güven GS. Altered tryptophan absorption and metabolism could underlie long-term symptoms in survivors of coronavirus disease 2019 (COVID-19). Nutrition. 2021;90:111308.

100. Shader RI. COVID-19, interferons, and depression: a commentary. Psychiatr Res. 2020;291:113198.

101. Palego L, Betti L, Rossi A, Giannaccini G. Tryptophan biochemistry: structural, nutritional, metabolic, and medical aspects in humans. J Amino Acids. 2016;2016:8952520.

102. Stone TW, Stoy N, Darlington LG. An expanding range of targets for kynurenine metabolites of tryptophan. Trends Pharmacol Sci. 2013;34(2):136-43.

103. Wurtman RJ, Wurtman JJ, Regan MM, McDermott JM, Tsay $\mathrm{RH}$, Breu JJ. Effects of normal meals rich in carbohydrates or proteins on plasma tryptophan and tyrosine ratios. Am J Clin Nutr. 2003;77(1):128-32.

104. Lederer A-K, Maul-Pavicic A, Hannibal L, Hettich M, Steinborn $\mathrm{C}$, Gründemann $\mathrm{C}$, et al. Vegan diet reduces neutrophils, monocytes and platelets related to branched-chain amino acids - a randomized, controlled trial. Clin Nutr. 2020;39(11):3241-50.

105. St-Onge M-P, Crawford A, Aggarwal B. Plant-based diets: reducing cardiovascular risk by improving sleep quality? Curr Sleep Med Rep. 2018;4(1):74-8.

106. Muscogiuri G, Barrea L, Savastano S, Colao A. Nutritional recommendations for CoVID-19 quarantine. Eur J Clin Nutr. 2020;74(6):850-1.

107. Casagrande M, Favieri F, Tambelli R, Forte G. The enemy who sealed the world: effects quarantine due to the COVID-19 on sleep quality, anxiety, and psychological distress in the Italian population. Sleep Med. 2020;1(75):12-20.

108. Gupta R, Grover S, Basu A, Krishnan V, Tripathi A, Subramanyam A, et al. Changes in sleep pattern and sleep quality during COVID-19 lockdown. Indian J Psychiatr. 2020;62(4):370-8.

109. Coiro MJ, Asraf K, Tzischinsky O, Hadar-Shoval D, TannousHaddad L, Wolfson AR. Sleep quality and COVID-19-related stress in relation to mental health symptoms among Israeli and US adults. Sleep Health. 2021;7(2):127-33.

110. Kocevska D, Blanken TF, Van Someren EJW, Rösler L. Sleep quality during the COVID-19 pandemic: not one size fits all. Sleep Med. 2020;76:86-8.

111. Sanlier N, Sabuncular G. Relationship between nutrition and sleep quality, focusing on the melatonin biosynthesis. Sleep Biol Rhythms. 2020;18(2):89-99.

112. Pengpid S, Peltzer K. Fruit and vegetable consumption is protective from short sleep and poor sleep quality among university students from 28 countries. Nat Sci Sleep. 2020;12:627-33.

113. Jyväkorpi SK, Urtamo A, Kivimäki M, Strandberg TE. Associations of sleep quality, quantity and nutrition in oldest-old men The Helsinki Businessmen Study (HBS). Eur Geriatr Med. 2021;12(1):117-22.
114. St-Onge M-P, Roberts A, Shechter A, Choudhury AR. Fiber and saturated fat are associated with sleep arousals and slow wave sleep. J Clin Sleep Med. 2016;12(1):19-24.

115. Sato-Mito N, Sasaki S, Murakami K, Okubo H, Takahashi Y, Shibata $\mathrm{S}$, et al. The midpoint of sleep is associated with dietary intake and dietary behavior among young Japanese women. Sleep Med. 2011;12(3):289-94.

116. Tan X, Alén M, Cheng SM, Mikkola TM, Tenhunen J, Lyytikäinen A, et al. Associations of disordered sleep with body fat distribution, physical activity and diet among overweight middle-aged men. J Sleep Res. 2015;24(4):414-24.

117. Kristensen NB, Madsen ML, Hansen TH, Allin KH, Hoppe C, Fagt $\mathrm{S}$, et al. Intake of macro- and micronutrients in Danish vegans. Nutr J. 2015;14(1):115.

118. Abbasi B, Kimiagar M, Sadeghniiat K, Shirazi MM, Hedayati M, Rashidkhani B. The effect of magnesium supplementation on primary insomnia in elderly: a double-blind placebo-controlled clinical trial. J Res Med Sci. 2012;17(12):1161-9.

119. Zhang Y, Chen C, Lu L, Knuston K, Carnethon M, Fly A, et al. Association of magnesium intake with sleep duration and sleep quality: findings from the CARDIA study. Curr Dev Nutr. 2021;5:1109-1109.

120. Pickering G, Mazur A, Trousselard M, Bienkowski P, Yaltsewa $\mathrm{N}$, Amessou M, et al. Magnesium status and stress: the vicious circle concept revisited. Nutrients. 2020;12(12):3672.

121. Wienecke E, Nolden C. Long-term HRV analysis shows stress reduction by magnesium intake. MMW Fortschr Med. 2016;158(Suppl 6):12-6.

122. Carfì A, Bernabei R, Landi F. Gemelli against COVID-19 post-acute care study group. Persistent symptoms in patients after acute COVID-19. JAMA. 2020;324(6):603-5.

123. Ali AM, Kunugi H. Skeletal muscle damage in COVID-19: a call for action. Medicina (Kaunas). 2021;57(4):372.

124. Elma Ö, Yilmaz ST, Deliens T, Coppieters I, Clarys P, Nijs J, et al. Do nutritional factors interact with chronic musculoskeletal pain? a systematic review. J Clin Med. 2020;9(3):702.

125. Choi KW, Somers TJ, Babyak MA, Sikkema KJ, Blumenthal JA, Keefe FJ. The relationship between pain and eating among overweight and obese individuals with osteoarthritis: an ecological momentary study. Pain Res Manag. 2014;19(6):e159-163.

126. Meleger AL, Froude CK, Walker J. Nutrition and eating behavior in patients with chronic pain receiving long-term opioid therapy. PM\&R. 2014;6(1):7-12.e1.

127. Batista ED, Andretta A, de Miranda RC, Nehring J, Dos Santos PE, Schieferdecker MEM. Food intake assessment and quality of life in women with fibromyalgia. Rev Bras Reumatol Engl Ed. 2016;56(2):105-10.

128. Tarleton EK, Kennedy AG, Rose GL, Littenberg B. Relationship between magnesium intake and chronic pain in US adults. Nutrients. 2020;12(7):2014.

129. Towery P, Guffey JS, Doerflein C, Stroup K, Saucedo S, Taylor J. Chronic musculoskeletal pain and function improve with a plant-based diet. Complement Ther Med. 2018;40:64-9.

130. McDougall J, Bruce B, Spiller G, Westerdahl J, McDougall M. Effects of a very low-fat, vegan diet in subjects with rheumatoid arthritis. J Altern Complement Med. 2002;8(1):71-5.

131. Clinton CM, O'Brien S, Law J, Renier CM, Wendt MR. Whole-foods, plant-based diet alleviates the symptoms of osteoarthritis. Arthritis. 2015;2015:708152.

132. Solway J, McBride M, Haq F, Abdul W, Miller R. Diet and dermatology: the role of a whole-food, plant-based diet in preventing and reversing skin aging-a review. J Clin Aesthet Dermatol. 2020;13(5):38-43.

133. Turner-McGrievy GM, Barnard ND, Scialli AR. A twoyear randomized weight loss trial comparing a vegan diet 
to a more moderate low-fat diet. Obesity (Silver Spring). 2007;15(9):2276-81.

134. Najjar RS, Feresin RG. Plant-based diets in the reduction of body fat: physiological effects and biochemical insights. Nutrients. 2019;11(11):2712.

135.• Doykov I, Hällqvist J, Gilmour KC, Grandjean L, Mills K, Heywood WE. 'The long tail of Covid-19' - the detection of a prolonged inflammatory response after a SARS-CoV-2 infection in asymptomatic and mildly affected patients. F1000Res [Internet]. 2021 Jan 8 [cited 2021 May 25];9. Available from: https:// www.ncbi.nlm.nih.gov/pmc/articles/PMC7745182/. The authors demonstrated that inflammatory pathways can remain perturbed up to 60 days after a SARS-CoV-2 infection in patients with longCOVID. Nutritional anti-inflammatory interventions are urgently warranted to reduce systemic inflammation in affected patients.

136. Mazza MG, Palladini M, De Lorenzo R, Magnaghi C, Poletti $\mathrm{S}$, Furlan R, et al. Persistent psychopathology and neurocognitive impairment in COVID-19 survivors: effect of inflammatory biomarkers at three-month follow-up. Brain Behav Immun. 2021;94:138-47.

137. Storz MA. How research on depression could now fundamentally change preventive cardiology. Eur J Prev Cardiol. 2020;30:2047487320915804.

138. Turner-McGrievy GM, Wirth MD, Shivappa N, Wingard EE, Fayad R, Wilcox S, et al. Randomization to plant-based dietary approaches leads to larger short-term improvements in Dietary Inflammatory Index scores and macronutrient intake compared with diets that contain meat. Nutr Res. 2015;35(2):97-106.

139. Kim M-S, Hwang S-S, Park E-J, Bae J-W. Strict vegetarian diet improves the risk factors associated with metabolic diseases by modulating gut microbiota and reducing intestinal inflammation. Environ Microbiol Rep. 2013;5(5):765-75.

140. Eichelmann F, Schwingshackl L, Fedirko V, Aleksandrova K. Effect of plant-based diets on obesity-related inflammatory profiles: a systematic review and meta-analysis of intervention trials. Obes Rev. 2016;17(11):1067-79.

141. Franco-de-Moraes AC, de Almeida-Pititto B, da Rocha FG, Gomes EP, da Costa PA, Ferreira SRG. Worse inflammatory profile in omnivores than in vegetarians associates with the gut microbiota composition. Diabetol Metab Syndr. 2017;9:62.

142. Shah B, Newman JD, Woolf K, Ganguzza L, Guo Y, Allen N, et al. Anti-inflammatory effects of a vegan diet versus the American Heart Association-recommended diet in coronary artery disease trial. J Am Heart Assoc. 2018 Dec 4;7(23):e011367. Shah et al. demonstrated that an 8-week vegan intervention can significantly reduce high-sensitivity C-reactive protein by $32 \%$. This approach could be useful to reduce systemic inflammation in patients with long-COVID.

143. Baden MY, Satija A, Hu FB, Huang T. Change in plant-based diet quality is associated with changes in plasma adiposity-associated biomarker concentrations in women. J Nutr. 2019;149(4):676-86.

144. Craddock JC, Neale EP, Peoples GE, Probst YC. Vegetarianbased dietary patterns and their relation with inflammatory and immune biomarkers: a systematic review and meta-analysis. Adv Nutr. 2019;10(3):433-51.

145. Mainardi T, Kapoor S, Bielory L. Complementary and alternative medicine: herbs, phytochemicals and vitamins and their immunologic effects. J Allergy Clin Immunol. 2009;123(2):283-94.
146. Ninfali P, Antonelli A, Magnani M, Scarpa ES. Antiviral properties of flavonoids and delivery strategies. Nutrients. 2020;12(9):E2534.

147. Zakaryan H, Arabyan E, Oo A, Zandi K. Flavonoids: promising natural compounds against viral infections. Arch Virol. 2017;162(9):2539-51.

148. Kim YS, Sayers TJ, Colburn NH, Milner JA, Young HA. Impact of dietary components on NK and Treg cell function for cancer prevention. Mol Carcinog. 2015;54(9):669-78.

149. Malter M, Schriever G, Eilber U. Natural killer cells, vitamins, and other blood components of vegetarian and omnivorous men. Nutr Cancer. 1989;12(3):271-8.

150. Haddad EH, Berk LS, Kettering JD, Hubbard RW, Peters WR. Dietary intake and biochemical, hematologic, and immune status of vegans compared with nonvegetarians. Am J Clin Nutr. 1999;70(3 Suppl):586S-593S.

151. Tong TYN, Key TJ, Gaitskell K, Green TJ, Guo W, Sanders TA, et al. Hematological parameters and prevalence of anemia in white and British Indian vegetarians and nonvegetarians in the UK Biobank. Am J Clin Nutr. 2019;110(2):461-72.

152. Jung C-H, Lee W-Y, Kim B-Y, Park SE, Rhee E-J, Park C-Y, et al. The risk of metabolic syndrome according to the white blood cell count in apparently healthy Korean adults. Yonsei Med J. 2013;54(3):615-20.

153. Gkrania-Klotsas E, Ye Z, Cooper AJ, Sharp SJ, Luben R, Biggs ML, et al. Differential white blood cell count and type 2 diabetes: systematic review and meta-analysis of cross-sectional and prospective studies. PLoS One. 2010;5(10):e13405.

154. Booth A, Reed AB, Ponzo S, Yassaee A, Aral M, Plans D, et al. Population risk factors for severe disease and mortality in COVID-19: a global systematic review and meta-analysis. PLoS One. 2021;16(3):e0247461.

155. Farmer B, Larson BT, Fulgoni VL, Rainville AJ, Liepa GU. A vegetarian dietary pattern as a nutrient-dense approach to weight management: an analysis of the national health and nutrition examination survey 1999-2004. J Am Diet Assoc. 2011;111(6):819-27.

156. Fresán U, Errendal S, Craig WJ. Influence of the socio-cultural environment and external factors in following plant-based diets. Sustainability. 2020;12(21):9093.

157. Mensink GBM, Lage Barbosa C, Brettschneider AK. Prevalence of persons following a vegetarian diet in Germany. $\mathrm{J}$ Health Monitor. 2016;1(2):2-14. https://doi.org/10.17886/ RKI-GBE-2016-039.

158. Paslakis G, Richardson C, Nöhre M, Brähler E, Holzapfel C, Hilbert A, et al. Prevalence and psychopathology of vegetarians and vegans - results from a representative survey in Germany. Sci Rep. 2020;10(1):6840.

159. Davey GK, Spencer EA, Appleby PN, Allen NE, Knox KH, Key TJ. EPIC-Oxford: lifestyle characteristics and nutrient intakes in a cohort of 33883 meat-eaters and 31546 non meat-eaters in the UK. Public Health Nutr. 2003;6(3):259-69.

Publisher's Note Springer Nature remains neutral with regard to jurisdictional claims in published maps and institutional affiliations. 